\title{
Osteosynthesis of Fracture Neck of Femur with High Valgus Angle in Young Adult with Post-polio Residual Paralysis: A Case Report and Review of Literature
}

\author{
Lavindra Tomar MS, MCh (UK), FICS ${ }^{1,4}$, Gaurav Govil M.S ${ }^{2,4^{*}}$, Pawan Dhawan M.S, DNB ${ }^{3,4}$ \\ ${ }^{I}$ Director \& Unit Head, Max Super Speciality Hospital, Patparganj, Delhi, India \\ ${ }^{2}$ Senior Orthopaedic Consultant, Max Super Speciality Hospital, Patparganj, Delhi, India \\ ${ }^{3}$ Attending Orthopaedic Consultant, Max Super Speciality Hospital, Patparganj, Delhi, India \\ ${ }^{4}$ Department of Orthopaedics, Max Super Speciality Hospital, 108 A, I.P. Extension, Patparganj, Delhi, India- \\ 110092
}

*Corresponding Author: Gaurav Govil M.S, D-101, Sunshine Helios, Sector 78, Noida, UP, India 201305

\begin{abstract}
Introduction: Poliomyelitis with flaccid asymmetric paralysis and muscle atrophy reduces stability, mobility and alters the gait pattern predisposing to falls. Post-polio residual paralysis (PPRP) patients are prone to fractures even after mild trauma. Abnormal skeletal deformation, associated muscle atrophy and poor bone mineral density presents unique challenges in management.

Case Report: We report a case of fracture neck of femur (FNOF) in a 22-year old young adult male PPRP patient managed with a 150-degree dynamic hip screw (DHS) with de-rotation screw (DS) fixation. The polio-affected limb had significant valgus deformity and low bone density. A sliding screw and plate construct along with DS allowed a controlled collapse after indirect reduction. An uneventful bony union and good functional recovery were noted. No avascular necrosis or implant failure was noted at a five-year follow-up period.
\end{abstract}

Conclusion: A meticulous pre-operative planning, customised surgical management protocol and need-based fracture fixation with emphasis on early rehabilitation will help to achieve a pre-injury ambulatory outcome. We reviewed the literature to ascertain management guidelines for FNOF in young adult with PPRP.

Abbreviations: FNOF: Fracture neck of femur, PPRP: Post-polio residual paralysis, LISS: Less invasive stabilization system, CCS: Cannulated cancellous screw, DHS: Dynamic hip screw, DS: De-rotation screw, ROM: Range of motion, THA: Total hip arthroplasty, HRA: Hemi-replacement arthroplasty

Keywords: Fracture neck femur; Hip fracture; Poliomyelitis; Post-polio residual paralysis; Hip osteosynthesis; Dynamic hip screw; De-rotation screw

\section{INTRODUCTION}

Developing countries have a large number of poliomyelitis survivors presenting with PPRP, prone to fractures after simple falls. The late eradication of poliomyelitis in developing countries has left both young and old polio survivors [1]. Studies give four times more fracture sustainability risk in the affected population $[1,2]$. The prevalence of FNOF in patients with PPRP is poorly described in the literature $[1,3,4]$.

Treatment of FNOF in poliomyelitis is challenging because of abnormal skeletal deformation such as significant coxa valga, increased pelvic tilt, excessive femoral anteversion and narrow medullary femoral canal $[1,2,3,4,5,6,7]$. Femoral neck bone mineral density is significantly reduced in poliomyelitis cases compared to age matched controls $[1,2,4$, 5]. Use of regular implants with regular neckshaft angle devices may not be a suitable choice $[5,6]$. The return to the pre-injury levels of function due to associated muscle atrophy, poor bone density, and inadequate fixation is associated with high morbidity, high risk of implant failure and late complications $[1,3,6]$. 
We report a case of FNOF in a young adult male managed with 150-degree DHS with DS allowing for an early mobilization with good functional outcome and return to preinjury ambulatory status. We review the available literature for FNOF management in PPRP.

\section{CASE REPORT}

A 22-year-old male had a FNOF after a simple fall. He had a history of paralytic poliomyelitis of right lower limb. He had an independent ambulatory status for his routine activities without any aid. Preoperative radiographs showed the right hip FNOF with significantly narrower femoral neck shaft and valgus deformities of the hips (Figure $1 \mathrm{a}$ and $1 \mathrm{~b}$ ). Preoperative templating of the contralateral hip revealed a high valgus neck shaft angle in excess of 135 degree.

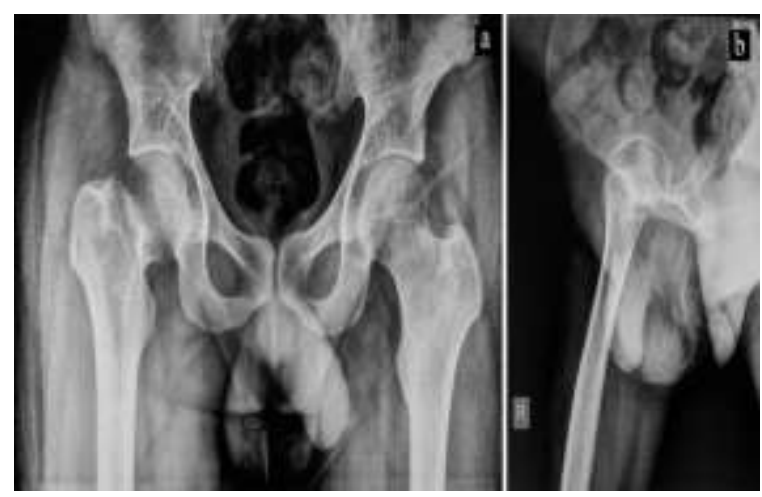

Figure1. Pre-operative radiographs with anteroposterior $(1 \mathrm{l})$ and lateral $(1 \mathrm{~b})$ view of the right hip FNOF.

Surgery was performed the same day of injury under general anaesthesia. Regular closed reduction on normal table was done before preparation and draping. The reduction was achieved by applying longitudinal manual traction to the fractured limb with $15^{\circ}$ of abduction and internal rotation of the hip. Fracture alignment was confirmed on both anteroposterior and lateral views and a hip valgus as anticipated was evident on fluoroscopy after reduction was achieved. A standard lateral approach was then used. A guide wire for the DHS was placed with a 150-degree angle guide seated on lateral femoral curvature and centred in anteroposterior and lateral view under fluoroscopic guidance. A de-rotation guide wire was placed superiorly to avoid displacement of fracture and abnormal femoral head rotation during screw placement. Triple reaming was done and a dynamic screw of appropriate length along with 150-degree dynamic plate construct was fixed with screws to distal femur. A simultaneous placement of DS was done to allow for a controlled collapse of fracture and achieve a rigid fixation construct. The final hardware placement was rechecked with fluoroscopic imaging in both planes before irrigation and wound closure (Figure 2 a and 2 b).

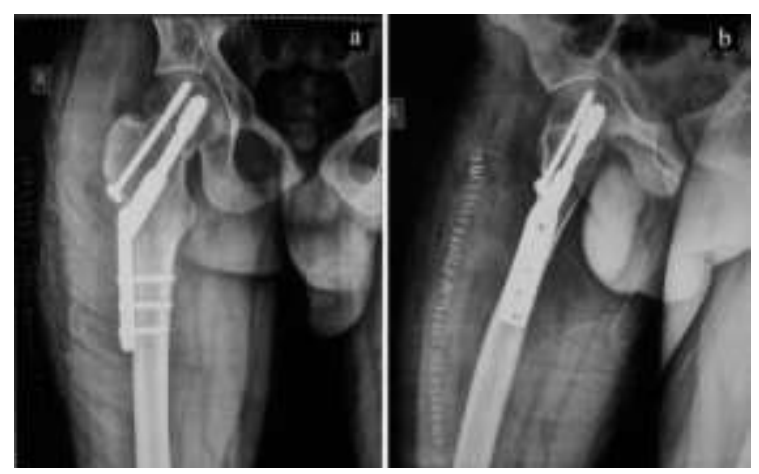

Figure2. Immediate post-operative radiographs with anteroposterior (2 a) and lateral (2 b) view of the right hip FNOF fixed with 150-degree DHS and DS

Range of motion (ROM) on bed was encouraged the second day after surgery and a toe-touch weight bearing was encouraged in immediate post-operative period. At six weeks, radiographic evaluation showed maintained fracture reduction and partial weight bearing was started. At three months full weight bearing was allowed when there were clear signs of healing on radiographic imaging (Figure 3 a and $3 \mathrm{~b}$ ). Union was confirmed at four months after operation (Figure $4 \mathrm{a}$ and $4 \mathrm{~b}$ ). Return to preinjury level of ambulatory status was uneventful. A mid-term evaluation at five years follow-up radiographs showed no avascular necrosis, implant failure or secondary arthritis and an independent unaided ambulation was preserved (Figure $5 \mathrm{a}, 5 \mathrm{~b}$ and $5 \mathrm{c}$ ).
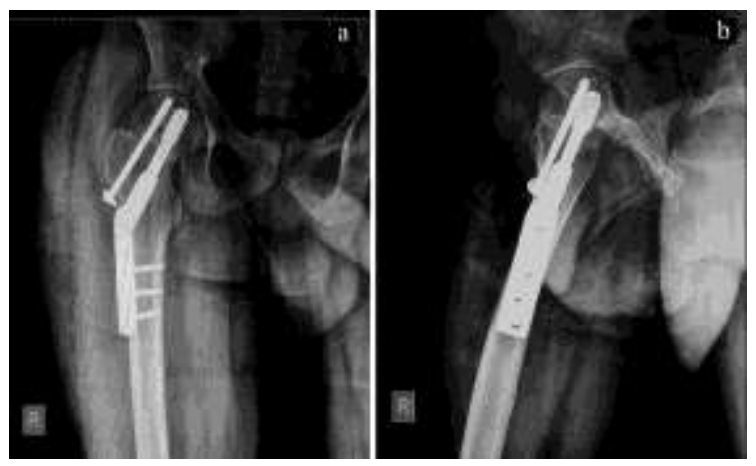

Figure3. Post-operative radiographs with anteroposterior (3 a) and lateral (3 b) view at three months showed good healing. 

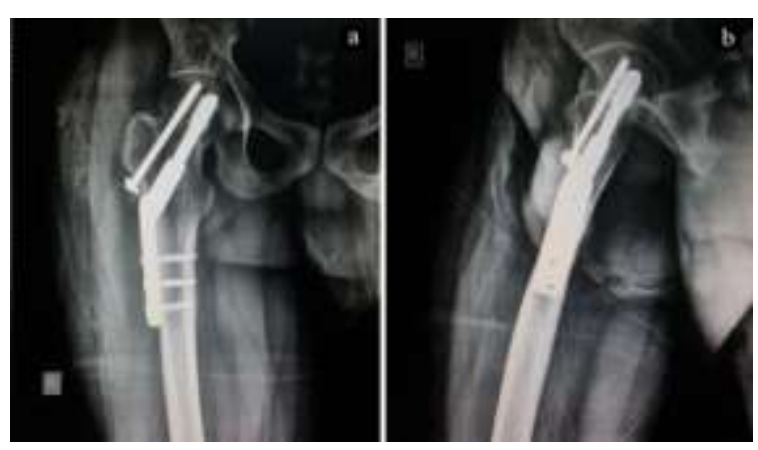

Figure4. Post-operative radiographs with anteroposterior (4 a) and lateral (4 b) view at four months showed good consolidation
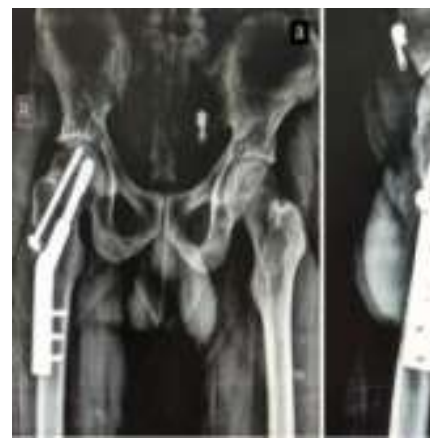

Figure5.

Follow-up
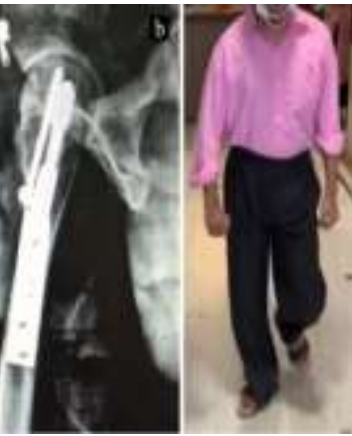
anteroposterior (5 a) and lateral (5 b) view at five years showed no avascular necrosis or secondary osteoarthritis and clinical photograph with full weight bearing on right lower limb with unaided walking $(5 \mathrm{c})$.

\section{DISCUSSION}

FNOF management in young adults is challenging. It's a fracture of necessity, requiring anatomical reduction and stable internal fixation. The choice of implant, use of reduction techniques and the type of approach are determined based on the location of fracture, its displacement, rotation and comminution. The aim is to preserve the natural hip anatomy and mechanics to allow good functional outcome.
An un-displaced FNOF is normally amicable to percutaneous in-situ internal fixation. However, a displaced fracture requires an open or a closed reduction technique. There is considerable debate regarding various reduction techniques with no clear superiority documented. It is of paramount importance to obtain an anatomic reduction. A mal-reduction has high risk of nonunion and avascular necrosis [8].

FNOF in young adult may be addressed by a number of surgical methods ranging from simple internal fixation, to internal fixation with non-vascularised grafts, to fixation with vascularised grafts, or internal fixation combined with valgus osteotomy to arthroplasty [5]. In young adults, every effort should be made to conserve the native femoral head and arthroplasty is considered to be a salvage option [5]. An associated poliomyelitis with osseous hypoplasia is not amenable to standard treatment options and presents challenges with fracture fixation.

There are numerous studies on the management of FNOF in young adults. However, literature for management of FNOF with osteosynthesis in PPRP limb is sparse. There are limited studies which discuss management of fractures in poliomyelitis and they normally include fractures at various bony sites with only few cases of FNOF reported. Sporadic case reports on different surgical techniques applied for FNOF management in PPRP are available [5, 6, $7,9]$ (Table 1). The studies with FNOF cases in PPRP are also limited $[2,4,10,11,12]$ (Table 2 ). No clear guidelines can be inferred and management was case based with customised implant selection for osteosynthesis.

Table1. Demographics of case reports on FNOF management in poliomyelitis

\begin{tabular}{|l|c|c|c|c|l|c|l|l|}
\hline \multicolumn{1}{|c|}{ Study } & Year & $\begin{array}{l}\text { Injury } \\
\text { pattern }\end{array}$ & $\begin{array}{l}\text { Age (in } \\
\text { years })\end{array}$ & Sex & Technique & $\begin{array}{l}\text { Union time } \\
\text { (in months })\end{array}$ & $\begin{array}{l}\text { Complication } \\
\text { /Limitation }\end{array}$ & \multicolumn{1}{|c|}{ Concerns } \\
\hline $\begin{array}{l}\text { Mootha } \text { et } \\
\text { al [5] }\end{array}$ & 2010 & $\begin{array}{l}\text { Fall from } \\
\text { bicycle }\end{array}$ & 32 & M & $\begin{array}{l}\text { Muscle } \\
\text { pedicle graft }\end{array}$ & 5 & $\begin{array}{l}\text { Second site } \\
\text { morbidity with } \\
\text { graft }\end{array}$ & $\begin{array}{l}\text { Femoral-acetabular } \\
\text { impingement, } \\
\text { osteoporosis }\end{array}$ \\
\hline $\begin{array}{l}\text { Babu } \text { et al } \\
\text { [7] }\end{array}$ & 2014 & Trivial fall & 28 & M & CCS & $>6$ & None & $\begin{array}{l}\text { Anteversion > 50 } \\
\text { degrees }\end{array}$ \\
\hline $\begin{array}{l}\text { Codesido } \\
\text { et al [9] }\end{array}$ & 2017 & Non-union & 53 & F & $\begin{array}{l}\text { CCS \& } \\
\text { Stem cell }\end{array}$ & 6 & None & Pseudo-arthrosis \\
$\begin{array}{l}\text { Yao } \text { et al } \\
{[6]}\end{array}$ & 2017 & Simple fall & 50 & F & LISS & 12 & Impingement & Osteoporosis \\
\hline Our case & 2020 & Simple fall & 22 & M & DHS + DS & 4 & None & $\begin{array}{l}\text { High valgus, } \\
\text { osteoporosis }\end{array}$ \\
\hline
\end{tabular}

Abbreviations: $M=$ Male, $F=$ Female $; F N O F=$ Fracture neck of femur, CCS=Cannulated cancellous screw, DHS = Dynamic Hip Screw, LISS= Less invasive stabilization system, DS = de-rotation screw 
Osteosynthesis of Fracture Neck of Femur with High Valgus Angle in Young Adult with Post-polio Residual Paralysis: A Case Report and Review of Literature

Table2. Studies on FNOF management in poliomyelitis

\begin{tabular}{|c|c|c|c|c|c|c|}
\hline Study & Year & Total PFF & FNOF & Age (in years) & Surgery procedure & Complication \\
\hline Kumar et al [10] & 2017 & 7 & 1 & 65 & HRA & None \\
\hline $\begin{array}{l}\text { Thirunarayanan et al } \\
{[11]}\end{array}$ & 2017 & 20 & 3 & $48 / 50 / 51$ & $\begin{array}{ll}2 \text { CCS } \\
1 \text { HRA }\end{array}$ & None \\
\hline $\begin{array}{l}\text { J Minto-Robinet et al } \\
{[4]}\end{array}$ & 2018 & - & 22 & $48-89$ (range) & $\begin{array}{l}\text { 8 Fixation (? screw) } \\
14 \text { Arthroplasty }\end{array}$ & - \\
\hline Gellman et al [12] & 2019 & 39 & Not clear & - & $\begin{array}{l}6 \text { DHS, } 3 \text { DCS, } \\
8 \text { CCS, } 3 \text { HRA }\end{array}$ & $16 \%$ overall \\
\hline $\begin{array}{l}\text { Checa-Betegon } \text { et al } \\
{[2]}\end{array}$ & 2020 & $54.2 \%(74)$ & 17 & 68 (mean) & $\begin{array}{l}\text { 35.3\% CCS, Rest } \\
\text { Arthroplasty }\end{array}$ & $11.4 \%$ \\
\hline
\end{tabular}

Abbreviations: $M=$ Male, $F=$ Female $; P F F=$ Proximal femur fracture, $F N O F=$ Fracture neck of femur, $C C S=$ Cannulated cancellous screw, DHS= Dynamic Hip Screw, DCS= Dynamic condylar screw, HRA=Hemireplacement arthroplasty.

Fixation with cannulated cancellous screw (CCS) in FNOF is frequently advocated in minimally displaced fractures in young adults. Avascular necrosis, non-union, screw cut-out, implant failure and secondary arthritis can occur. In a PPRP limb with altered anatomy, reduction technique and conventional implant placement presents with challenges as a perfect triangular relationship may not be possible to obtain because of small neck [1]. The altered anteversion may require a posterior entry point closer to buttocks to negotiate the wire into the neck and coxa valga may require an unusual abduction or adduction for reduction [1, 7]. A case report on paralytic hip with FNOF managed with CCS showed good union [7]. FNOF non-union after a missed injury in a polio affected leg in an elderly treated with CCS and percutaneous autologous injection of processed total nuclear cells mixed with putty demineralized bone matrix also showed good outcome. A viable head on an MRI reinforced that osteosynthesis precedes a hip arthroplasty procedure [9]. A study by J. Mingo-Robinet et al (2018) included eight patients of FNOF treated by internal fixation. The internal fixation method was done by screws however, comments on difficulties and intraoperative complications were inconclusive [4].

Osteosynthesis with DHS in FNOF has been advocated as a reliable procedure to regain a physiological hip in young adults $[13,14]$. In PPRP, the high femoral neck shaft valgus angle, altered anteversion and poor bone stock presents challenges with a routine DHS fixation. Paediatric DHS, addition of DS and appropriate angle construct can be used for stable fixation. DHS with DS will provide better stable fixation [14]. We report surgical fixation with DHS with
DS in PPRP limb with good outcome. No study for comparison could be identified. Thirunarayanan $\mathrm{V}$ et al used DHS for trochanteric fracture fixation in poliomyelitis with a 135-degree DHS and it showed good results with standard operating technique by placing guide wire in central position of femoral head and neck [11].

Use of a paediatric DHS was reported for fixation in a neglected FNOF along with graft augmentation procedure. However, there was no mention of the DHS angle used [5]

Management of two hip fractures with poliomyelitis sequelae (one FNOF and another subtrochanteric fracture) by using the reverse less invasive stabilization system (LISS) plating technique was done with a successful outcome [6]. The reverse LISS plating had the advantages of good angular stability and biological fixation with limited damage to the local blood supply when applied in proximal femur fractures [6]. A satisfactory antirotational, anti-angulation, and anti-pull out stability in osteoporotic bone was advocated with LISS plates. Implant failure and loss of fixation have been reported in proximal femur fractures treated with plating. Delayed weight bearing with reverse LISS technique was cause of concern.

A primary fixation or a primary arthroplasty is a matter of debate. Fractures not amicable to adequate stable fixation in young adults may require arthroplasty. Fixation failures of FNOF presenting with long term sequalae of avascular necrosis of femoral head and secondary osteoarthritis require a salvage complex hip arthroplasty procedure [1]. 
In PPRP limb, consideration during arthroplasty should be given to the use of small slender femoral stems, constructs that allow for control of version, and strategies to mitigate the risk of instability (HRA, dual mobility, constraint) [1,3]. A cemented arthroplasty in poor bone stock and an uncemented THA in good bone stock has been commonly advocated advocated and this has been summarised by J. MingoRobinet et al [4]. Any revision arthroplasty at a later age will present complex management challenges.

Postoperative rehabilitation in PPRP plays a major role in attaining the preinjury ambulatory status with emphasis on early weight bearing and active range of motion with a dedicated physiotherapy team $[1,3,10]$. Primary hip arthroplasty in young adults with PPRP, allowed an early rehabilitation and weight bearing potential. Any delay increased the muscle wasting and diminished the potential to achieve the pre-injury functional capability.

In summation, FNOF in PPRP requires a thorough preoperative evaluation, assessment of possible surgical techniques applicable, ready availability of implant inventory for a stable fixation and an early rehabilitation ambulation protocol to ensure a good functional outcome.

\section{CONCLUSION}

Poliomyelitis presents a unique orthopaedic challenge for management of FNOF as conventional methods are not applicable and failure rates are high.

A meticulous pre-operative planning ensures better implant selection for a stable fixation of FNOF. Fixation should allow early rehabilitation in a young adult with PPRP to achieve a pre-injury ambulatory status.

\section{ETHIC APPROVAL}

Not applied as a retrospective case study.

\section{CONSENT For PUblication}

The patient was informed that data from the case would be submitted for publication and patient gave the consent.

\section{ACKNOWLEDGEMENTS}

None to declare

\section{CONFLICTS OF INTEREST}

None to declare

ARC Journal of Orthopedics

\section{REFERENCES}

[1] Gupta M., Jain V.K., Upadhyaya G.K. and Arya R.K., Comprehensive review of challenges associated with management of lower limb fractures in poliomyelitis patients, Journal of Clinical Orthopaedics and Trauma. 7(4), 276-81 (2016).

[2] Checa Betegón P., Valle Cruz J., García Coiradas J., Rodríguez González A., González Pérez A., Torrecilla Cifuentes E. and Marco F., Fractures in patients with Poliomyelitis: Past or current challenge, Injury. (2020). doi:10.1016/j.injury.2020.02.029

[3] Garceau S.P., Igbokwe E.N., Warschawski Y., Neufeld M.E., Safir O.A., Wade J.P. and Wolfstadt J.I., Management options and outcomes for patients with femoral fractures with post-polio syndrome of the lower extremity, JBJS Reviews. 8(6), e0146-e0146 (2020).

[4] Mingo-Robinet J., Alonso J.A., MorenoBarrero M., González-García L., Garcia-Virto V., Aguado H.J., Technical aspects and complications in the surgical treatment of Poliomyelitis affected lower limb fractures, Revista Española de Cirugía Ortopédica y Traumatología (English Edition). 62(4), 257266 (2018).

[5] Mootha A.K., Sen R.K., Aggarwal S., Bali K. and Saini R., Management of a Neglected Femoral Neck Fracture in a Limb Affected by PoliomyelitisA Case Report, Hip International. 21(2), 267-269 (2011).

[6] Yao C., Jin D. and Zhang C., Reverse Less Invasive Stabilization System (LISS) plating for proximal femur fractures in poliomyelitis survivors: a report of two cases, The American Journal of Case Reports. 18, 1209 (2017).

[7] Babu S.S., Babu T.S., Kiran K.R., Sudhakar G. and Sridevi M.U., Difficulty in fixation of fracture neck of femur in a paralytic hip: a case report, Journal of Evolution of Medical and Dental Sciences. 28, 3(30), 8484-90 (2014).

[8] Pauyo T., Drager J., Albers A. and Harvey E.J., Management of femoral neck fractures in the young patient: A critical analysis review, World J Orthop. 5(3), 204-217 (2014).

[9] Codesido M.A., Weil Y., Liebergall M., Mosheiff R. and Khoury A., Femoral neck pseudoarthrosis in a polio patient treated with closed reduction and cell therapy, Trauma case reports. 8, 36-40 (2017).

[10] Kumar T.S., Senthilnathan A. and Prabhakar R., Choice of implants in management of fractures in patients with post-polio residual paralysis, Int J. Orthop. Sci., 3, 577-83 (2017). 
[11] Thirunarayanan V., Ramprasath D.R. and Rajan A., Assessment of bone geometry and its considerations in implant selection for polio affected femoral fractures: An outcome analysis, International Journal of Orthopaedics. 3(1), 441-8 (2017).

[12] Gellman Y.N., Khoury A., Liebergall M., Mosheiff R. and Weil Y.A., Outcome of femoral fractures in poliomyelitis patients, International Orthopaedics. 43, 11 (2019).

[13] Schwartsmann C.R., Jacobus L.S., Spinelli L.D., Boschin L.C., Gonçalves R.Z., Yépez
A.K. Barreto R.P., and Silva M.F., Dynamic hip screw for the treatment of femoral neck fractures: a prospective study with 96 patients, International Scholarly Research Notices. Article ID 257871 (2014).

[14] Siavashi B., Aalirezaei A., Moosavi M., Golbakhsh M.R., Savadkoohi D. and Zehtab M.J. A comparative study between multiple cannulated screws and dynamic hip screw for fixation of femoral neck fracture in adults, International Orthopaedics. 39(10), 2069-2071 (2015).

Citation: Lavindra Tomar, Gaurav Govil, Pawan Dhawan. Osteosynthesis of Fracture Neck of Femur with High Valgus Angle in Young Adult with Post-polio Residual Paralysis: A Case Report and Review of Literature. ARC Journal of Orthopedics. 2020; 5(2):14-19. DOI: https://doi.org/10.20431/2456-0588.0502003.

Copyright: (C) 2020 Authors. This is an open-access article distributed under the terms of the Creative Commons Attribution License, which permits unrestricted use, distribution, and reproduction in any medium, provided the original author and source are credited. 